\title{
Optics education for multidisciplinary students: how to focus on the relationship between optical technology and human civilization in group discussion
}

Xiaotong Li, Qing Yang, Ke Si, Kaiwei Wang

Xiaotong Li, Qing Yang, Ke Si, Kaiwei Wang, "Optics education for multidisciplinary students: how to focus on the relationship between optical technology and human civilization in group discussion," Proc. SPIE 11143, Fifteenth Conference on Education and Training in Optics and Photonics: ETOP 2019, 1114324 (2 July 2019); doi: 10.1117/12.2523858 Photonics: ETOP 2019, 2019, Quebec City, Quebec, Canada 


\title{
Optics education for multidisciplinary students: how to focus on the relationship between optical technology and human civilization in group discussion
}

\author{
Xiaotong Li, Qing Yang, Ke Si, Kaiwei Wang* \\ State key laboratory of modern optical instrumentation, College of optical science and engineering, \\ Zhejiang University, Hangzhou 310027, P. R. China
}

\begin{abstract}
Optics and light-based technology are becoming more and more important as a cross-field of new science and engineering, and the scope of optics education should be extended. Since 2018, in Zhejiang University a new wave of general education reform has started, and our course Light-based Science and Technologies and Human Civilization has become a common core course. In the last 3 years our students mainly come from science and engineering, only a few students come from social science. From now on we will offer this course to multidisciplinary students, especially the students of politics, economics, law and arts. In this paper we present our learning organization, especially the group discussion in multidisciplinary students. The students from different specialties are divided into one group. The discussion topics are about research methodology, famous arguments in optics history, optics in daily life and imagination of the future.
\end{abstract}

Keywords: Optics education, general education, common core course, multidisciplinary, group discussion, human civilization, teamwork

\section{INTRODUCTION}

Light is the source of life. From the ancient time to today, we cannot imagine the world without light. Plants cannot grow without light. Without plants, animals and mankind would have no food. Nowadays, there are more and more research fields have something to do with light and optics. Optics and optical technologies have brought well-being to our society. Laser, semi-conductor, photography, telescope, microscope and imaging are used in a lot of research fields, and become indispensable means for exploring our universe and ourselves. More importantly, light-based science and technology are not only academic research fields, but also go into our everyday life, push our society forward and bring us more freedom. By the means of optical technology, we can know the information of the other hemisphere in a flash, we can diagnose some diseases early and bring new hope to the patients. Now we can do many things that we cannot imagine before with the help of optical technologies.

Unfortunately, due to the lack of optics education in high schools in China and the pressure of college entrance examination, the fresh students in our universities have only a little knowledge about optics and optical technologies. They use mobiles to take photos in daily life, but they think optics as a strange research field. Particularly in the specialties of Liberal and Arts, the students think optics difficult and far away from us.

Since 2015, the International Year of Light and Light-based Technologies, we offered the course Light-based Science and Technologies as a general education course for multidisciplinary students. In a new wave of general education reform started in 2018 in Zhejiang University, this course became a common core course, and the credits has become 3 from 2. This gives us an opportunity to connect optics with different specialties closely, and to offer an better optics education to multidisciplinary students.

Researchers said, "In fact optics is itself presents multidisciplinary collection of independent scientific areas from one hand and was a generator of new fields of knowledge from the other hand." ${ }^{[1]}$ In 2017, we have report some contents and teaching organization of this course ${ }^{[2]}$. In this paper we describe how to organize the group discussion focused on the relationship of science, technology and human society.

*wangkaiwei@zju.edu.cn; phone (86)571-87953154-805; fax (86)571-87951617; opt.zju.edu.cn 


\section{OUTLINES OF THE COURSE}

As a general education course and a common core course, the students come from variety disciplines. They have little knowledge of optics and optical technologies. This means the contents must be popular and attractive. At the conference of ETOP 2017, we presented some contents of this course. After these years of efforts, the teaching systems of this course has been basically decided. Based on the history of optics, we take into account popular optical knowledge, academic and interesting, with special emphasis on humanism.

The outline of the course is in Table 1. Every week the students study theories for 2 class hours and discuss for 2class hours.

Table 1. Outline of the course

\begin{tabular}{|c|c|c|}
\hline \multicolumn{3}{|r|}{ OUTLINE OF THE COURSE } \\
\hline Unit & $\underline{\text { Week }}$ & Content \\
\hline 1 & 1 & $\begin{array}{l}\text { Optics in ancient times, optics in Mozi, geometrical optics in ancient } \\
\text { Greece and civilization in ancient Greece, the developments in optics in } \\
\text { Qin and Han dynasties in China }\end{array}$ \\
\hline 1 & 2 & $\begin{array}{l}\text { Geometrical optics in the Middle East, geometrical optics in Europe and } \\
\text { the invention of spectacles, optics in Song and Yuan dynasties in China }\end{array}$ \\
\hline 2 & 3 & $\begin{array}{l}\text { Leonardo da Vinci's arts: light and image, Snell's law, optical } \\
\text { achievements of amateur scientist Fermat, Galileo discovered the new } \\
\text { universe }\end{array}$ \\
\hline 2 & 4 & $\begin{array}{l}\text { The invention of microscope, the observation of Levenhoek and the } \\
\text { establishment of microbiology, dispersion phenomenon and theory, the } \\
\text { arguments between particle theory and wave theory }\end{array}$ \\
\hline 3 & 5 & $\begin{array}{l}\text { Principles of photography, Louis Daguerre and camera, the development } \\
\text { of photography since 19th century, the photos as historical memory, } \\
\text { image processing }\end{array}$ \\
\hline 3 & 6 & $\begin{array}{l}\text { Maxwell equations, Ernst Abbe, Otto Schott and Carl Zeiss and their } \\
\text { companies, CCD and digital imaging, integrated circuits and lithography } \\
\text { technology, photo-electric information conversion }\end{array}$ \\
\hline 4 & 7 & $\begin{array}{l}\text { Three dark clouds in physics, the wave theory and De Broglie, Albert } \\
\text { Einstein's letter and Erwin Schrodinger's equation, photoelectric effect }\end{array}$ \\
\hline 4 & 8 & $\begin{array}{l}\text { Stimulated radiation and the invention of laser, laser and application in } \\
\text { many fields, optical communication and the Internet, optical workshop } \\
\text { testing }\end{array}$ \\
\hline 5 & 9 & Machine vision, illumination technology and illumination art \\
\hline 5 & 10 & Display technology, remote sensing, imaging detection \\
\hline 6 & 11 & $\begin{array}{l}\text { Spectral technology and application in many fields, spectral image } \\
\text { processing and fusion }\end{array}$ \\
\hline 6 & 12 & Optics is an interdisciplinary field, spectroscopy and other disciplines \\
\hline 7 & 13 & Optics is an interdisciplinary field, optics and other disciplines \\
\hline 7 & 14 & Optics is an interdisciplinary field, optics and other disciplines \\
\hline 8 & 15 & $\begin{array}{l}\text { A summary of the Nobel Prize related to light-based science and } \\
\text { technologies in history, Light-based science and technologies in history }\end{array}$ \\
\hline 8 & 16 & Presentation and drama by students \\
\hline
\end{tabular}




\section{DISCUSSION MATERIALS AND TOPICS}

\subsection{Popular and attractive course and discussion}

As shown in Table 1 that there are two main lines in this course. One is according to the time sequence of historic events, and the other is according to academic fields. This is because in modern time optics has become an interdisciplinary field and has many sub-discipline. Our goal is to connect the past and now, history and real life, daily life and universe, optics and multidisciplinary fields, such as politics, economics, law and arts, to give multidisciplinary students the opportunities to learn research methods, to communicate with the students from other specialties, to understand the benefits that optics has brought and will bring to the people and the world, and to note that light-based technologies may bring an uncertain future to human being. These are popular and attractive.

Comparing a professional optical course, we collect the teaching and discussion materials in a much larger range.

\subsection{Discussion on academic research methodology}

This is due to that our course is defined as a scientific research and creation course. An important task of this course is to teach the students research methodology which can be used in multidisciplinary areas.

1. induction and deduction

In history of optics, there are many examples to teach students the way of science proceeds and to introduce the right spirit of critical analysis, building and testing of models, etc. ${ }^{[3]}$ We mainly collect the processes and methods of major scientific discoveries in history. For example, pinhole imaging and the experiments by Mozi, Ptolemy's refraction experiment, Reflective Optics written by Euclid, the refraction law of Snell. From these laws Fermat's principle was summarized. This is a process of induction. But if we want to deduce these laws about light propagation, the start point is Maxwell's equations. Induction and deduction are the same important in scientific discovery. The students are also asked to present their own research methods.

\section{Imaging, prediction, experimentation and confirmation}

Maxwell predicted the existence of electromagnetic waves and founded Maxwell's equations in 1864 by summarizing previous studies and mathematical derivation. Unfortunately, Maxwell's equations are not well known in 20 years. Only a few people could understand his theory. About 20 years later, Hertz published a series of papers that allowed Maxwell's theory to spread in Europe, and then he proved that light is an electromagnetic wave by experiments.

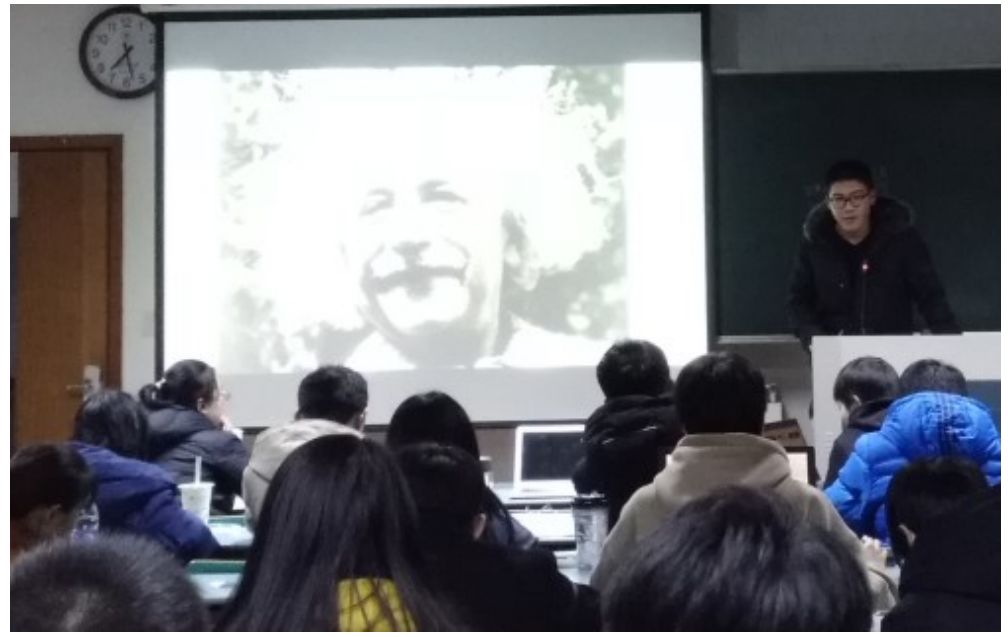

Figure 1. A student were telling the story of imaging, prediction experimentation and confirmation.

The milestone relation between particles and waves was discovered by De Broglie in the period of 1923 to 1924. In this discovery, an important factor is the imagination ability of De Broglie. In 1924, De Broglie presented the possibility of wavelike properties of electrons. The communication between Einstein, De Broglie and Schrödinger led to Schrödinger's equation. 
Another typical example is Einstein's prediction and the invention of laser ${ }^{[4]}$. Einstein's presented his prediction about the possibility of stimulated radiation in his paper published in 1917. About 40 years later, in 1958, Townes and Shawlow published a paper in Physical Review and proposed the prototypes of laser devices. In 1960 Maiman built the first laser device.

After the discussion on this topic, the students shared the stories and methods of scientific research, as shown in Figure 1.

\subsection{Discussion on academic argument}

Arguments are very important to find truth, this must be based on facts. Sometimes arguments were controlled by authorities and not equality and justice. A typical example is about Galileo's telescope and his observation.

Since 17th century, the research on the nature of light has continued for several centuries. The debate between particle theory represented by Newton, and wave theory represented by Huygens lasted for centuries, and particle theory dominated until the end of 18th century. At the beginning of the 20th century, Einstein unified particle theory and wave theory, and put forward the wave-particle duality ${ }^{[5]}$. Now the wave-particle duality of light is recognized by people.

Several important scientists involved in the debate, such as Huygens, Fresnel, Thomas Young, etc. Based on their experiments and observations, they presented their own points of view and showed critical spirit and scientific spirit. The debate also indicates a man's perception is often limited by the condition and the angle of observation. Opening up one's mind and developing critical thinking are important for discovering the truths.

During the discussion, the students wrote their own plays and performed this cross-century academic debates, as shown in Figure 2.

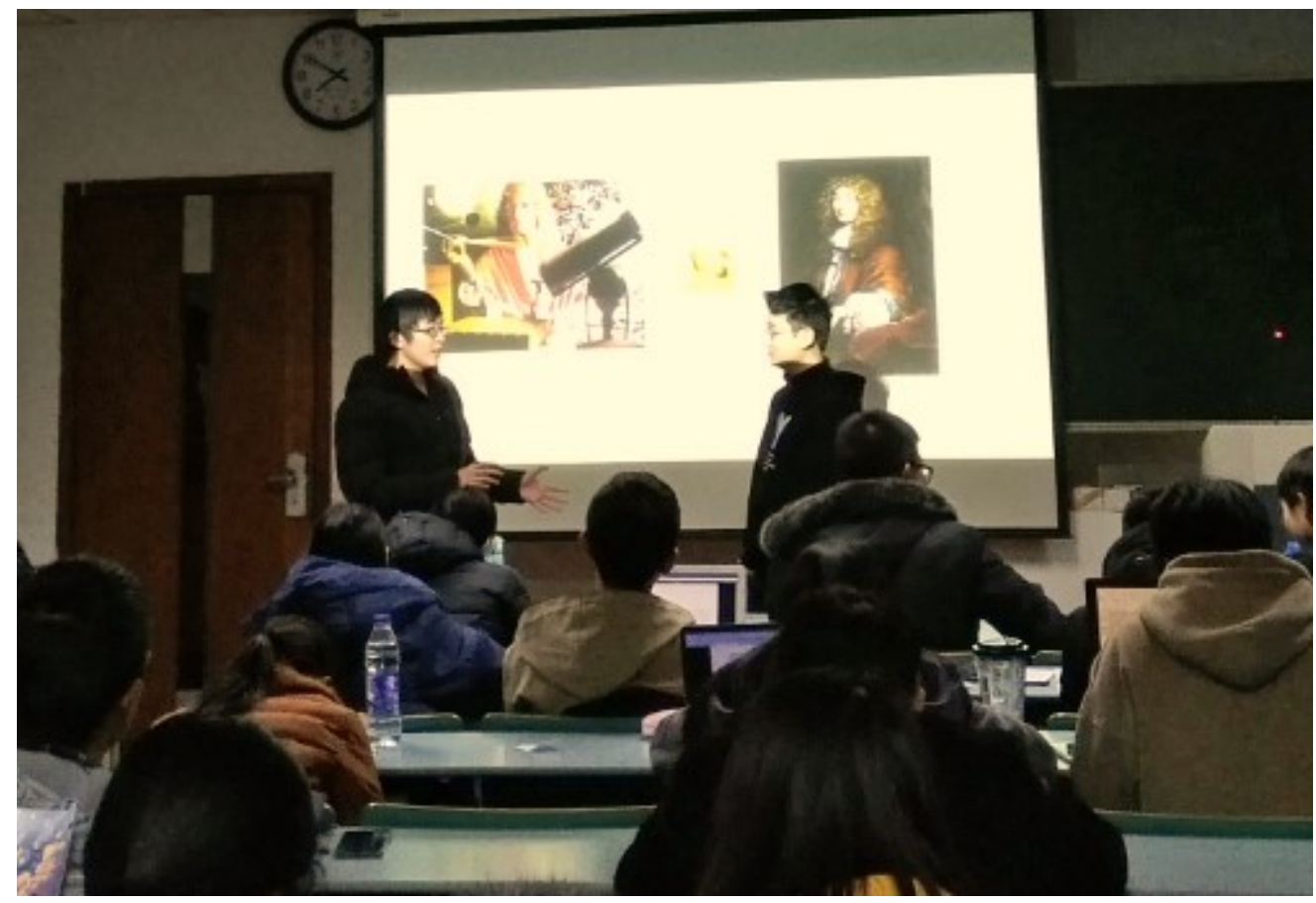

Figure 2. Two students were simulating a dispute between particle theory represented by Newton and wave theory represented by Huygens. The actor on the left played Newton, and the actor on the right played Huygens

\subsection{Discussion on optics in everyday life}

This discussion focuses on optics in everyday life, and there are several discussion topics. Photography and historical memory are the most important topics. We show some influential photos in history at first, and then ask the students to search for photos and take some photos by themselves. This discussion gives them a great space for imagination and thought. They are not only interested in photography technology, but also very enthusiastic in making their own photo collections. Some student groups collect the photos related to the same subject, and some students collect and list the old photos of their family in chronological order. They all realize that these photos are valuable historical memories of a land 
or a group of people. In their report, they have recognized the contribution of photography and photos in reducing poverty, raising the level of national education and describing the common destiny of human being in particular.

In Figure 3, the photo named "I want to go to school" by Xie Hailong is shown. This is a propaganda symbol of China's Hope Project. This photo and Victory Kiss by Alfred Eisenstaedt, War and Peace by Chen Fuli, and many other historical photos often become hot topics in discussion, and the photographers are respected by our students.

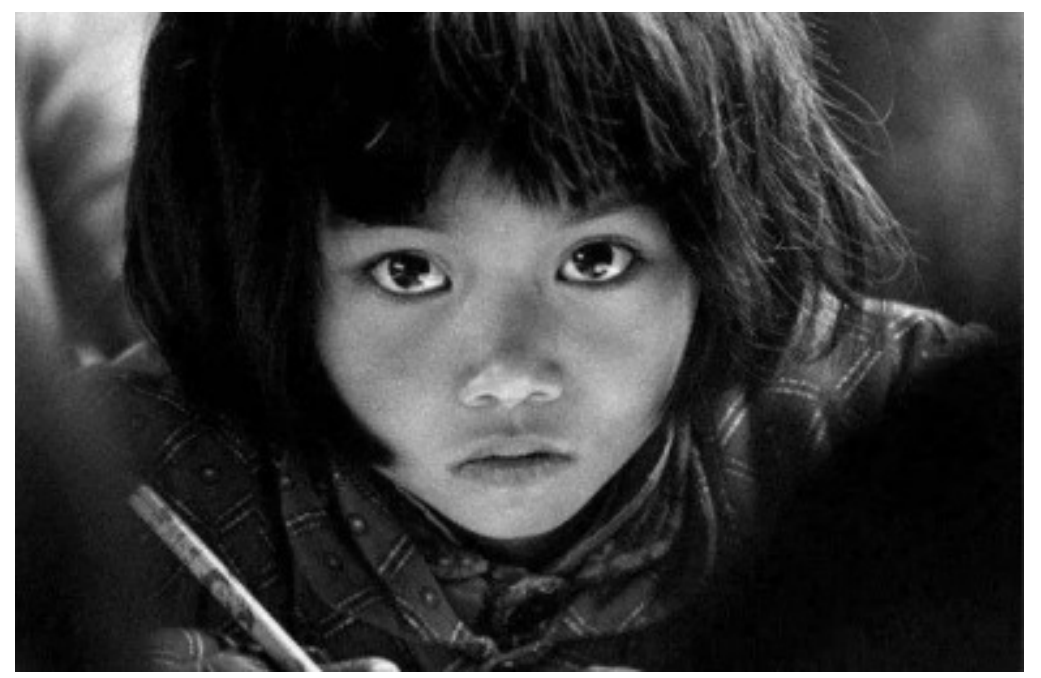

Figure 3. The photo named "I want to go to school", published in 1991, is a propaganda symbol of China's Hope Project.

\subsection{Discussion on cross-discipline and the future of mankind}

The cross-discipline of light and brain science, and artificial eyes and blind help are typical examples of light-based technology directly serving mankind. Associate professor Wang Kaiwei, one of the authors of this paper is keen on helping the blind to see the beautiful world, and his students have set up a company to develop visual aids to help the blind, and won the National Innovation and Entrepreneurship Award. From this point of view, the students have expressed concern for people with disabilities. This do not mean to provide them with special care. What the disabilities need is not mercy. Many of them are self-reliant and their minds are full of independent idea. They do not like to be cared for by others. They want equal opportunities to learn, to work, and to serve the human society. We still have a lot of things to do in that regard. We hope that every classmate who has learned this course has such a goal, with technology and love to break through the bondage of disease, to create opportunities for free development of the people, so that the world will be more equal and beautiful.

The students from department of politics point out that optical communication and the Internet make it easier for humans to obtain information. This make humans be freer and more equal. Certainly, they discuss the problems of digital gap. The students from agronomy and medical science are interested in the application of spectroscopy in food and drug safety. The students from economic discipline also have the topic of counterfeit money identification. Each student can find their own interest and the intersection point of optics and their own discipline in discussion.

\section{DISCUSSION ORGANIZATION}

Every two weeks we give 5 or 6 discussion topics. In the discussion each student group is composed of students from different discipline, so that they communicate from different perspectives. After 2 times of discussion, they submit a discussion report that writes the topics and the views they discussed, the process of discussion and the conclusions they obtained.

At first, the students wanted to be in one group with their classmates in the same discipline, because they knew each other well and some were good friends. After a semester of discussion, they found that the diversity of disciplines in one group was very helpful for opening the mind.

The following is a passage in a discussion report: 
"We come from different disciplines. In this semester we also learned about the cross-disciplines we might involve in the future. Our discussion brought us to brainstorm, and gave us the chance to meet a lot of partners from different disciplines, and contact different thoughts and research areas that had never been learned before. "

\section{CONCLUSION}

The teaching design and discussion has been accepted and appreciated by the students. In our university, the students must evaluate their teachers. Our students gave us high scores. In the autumn-winter semester of 2018-2019, the students gave this course an excellent grade score of 4.958/5. At the end of the semester, the students wrote the following in their final report:

"We learned from this course the history of optics, the development of optics and the great achievements of optics and the bright future. Light is everywhere and is closely to our lives. Light brings a lot of unexpected things to our lives and the future of the world."

"For a long time, the isolated development of the single scientific field has become more and more difficult, and the main contemporary scientific and technological problems and social problems have become highly integrated. These problems should be solved with the knowledge of many disciplines and various technical means. Now science often get some inspiration or get some solutions from other disciplines. Schools should be able to provide multidisciplinary education, and multidisciplinary cooperation in scientific research should be encouraged. This will be help for obtaining inspiration from different disciplines and good for future development."

"We should learn to open up our mind and integrate knowledge in many fields. The classification of disciplines in the Renaissance was not clear, so many generalists made great achievements in that time. Today, the classification of disciplines is clear, and scientists have their own specialized fields. Our research field is not as extensive as the predecessors. So it is necessary for us to cooperate exchange idea with the researchers from other fields and, then to give birth to new discoveries."

\section{ACKNOWLEDGEMENT}

All the work in this paper is supported by the project of General Education Reform of Zhejiang University.

\section{REFERENCES}

[1] S.K.Stafeef and M.G.Tomilin, "Optics history as effective instrument for education in optics and photonics," Education and Training in Optics and Photonics, OSA Technical Digest Series (CD) (Optical Society of America, 2009), paper ESB3.

[2] Li Xiaotong, Wang Kaiwei, Yang Qing, Si Ke, "Light-based science and technologies and human civilization: An optical course for general education, " Proc. SPIE, 10452, 104521K(2017).

[3] Vázquez D., González-Cano A., Díaz-Herrera N., Llombart N., Alda J., "History of optics: A modern teaching tool," Proc. SPIE 8481, 84810U(2012).

[4] Xiao Rupo, Yang Xinnan(translation), "August and September in physical history, "Modern physical knowledge, 2008, (5):64-65(2008) .

[5] Fang Zaiqing, Huang Jia, "From Huygens to Einstein: Unremitting pursuit for the nature of light," Science, 67(3):30-34(2015) . 